\title{
Trastuzumab as Single Agent Therapy for HER2-Positive Metastatic Breast Cancer
}

\author{
Priya Rastogi Nancy E. Davidson \\ University of Pittsburgh Cancer Institute, Pittsburgh, PA, USA
}

Trastuzumab is an integral part of therapy for patients with human epidermal growth factor receptor 2 (HER2)-positive breast cancer. Its activity as a single agent was demonstrated in several phase II trials. One critical trial evaluated trastuzumab as a single agent in women with HER2-positive breast cancer who have not previously received chemotherapy for metastatic disease [1]. The response rate was $26 \%$; and the clinical benefit rate was $38 \%$ in all assessable patients. The median survival was 24.4 months, which is comparable with the survival rate in the pivotal phase III combination trial of chemotherapy and trastuzumab which will be discussed below [2]. This trial demonstrated that single agent trastuzumab is active and an important treatment option in HER2-positive metastatic breast cancer.

Another large phase II trial indicated that trastuzumab monotherapy is active in HER2-positive metastatic breast cancer in women previously treated with chemotherapy for metastatic disease [3]. A total of 222 women with HER2-positive metastatic breast cancer that had progressed after one or two chemotherapy regimens were enrolled in this trial. The objective response rate was $15 \%$ (reviewed by an independent response evaluation committee) in the intent-to-treat population. The median duration of response was 9.1 months and the median duration of survival was 13 months.

In this issue of OnKologie Clemens et al. [4] present another report of the activity of single agent trastuzumab in patients with HER2-positive breast cancer who had previously received at least one chemotherapy regimen for metastatic disease. This report is of interest because it contains information gleaned from an expanded access trial before trastuzumab was made available in clinical practice in Germany. It contains data from 70 patients enrolled from 28 institutions across Germany during a one-year period in 19992000 and is therefore inclusive in scope. Eligibility criteria were relaxed with regard to extent of disease and previous types of therapy but a stringent definition of positive HER-2 as $3+$ by immunohistochemistry or $2+$ with a positive FISH assay was employed. Trastuzumab dose and schedule were standard. The overall response rate was $19 \%$ and disease stabilization was reported in an additional $29 \%$ of patients. Single agent trastuzumab was well tolerated. The most frequent adverse event was infusion-related syndrome, and symptomatic heart insufficiency of uncertain type was reported in 3 cases. Thus, in aggregate, this case series validates the efficacy and toxicity results of other trials of monotherapy with trastuzumab [3] although the frequency and type of cardiac events are more difficult to compare across different trials due to differences in definitions of a cardiac event.

This report also raises several directions for the future. A major question is the role of combination therapy with trastuzumab and other agents including chemotherapy or other targeted agents. The pivotal phase III trial of first-line trastuzumab with various chemotherapy regimens compared to chemotherapy alone demonstrated a significant improvement in survival (25.1 versus 20.3 months) and overall response (50 versus $32 \%$ ) [2]. This study led to the approval of trastuzumab with paclitaxel for first-line treatment of HER2-postive metastatic breast cancer as well as the conduct of several trials of combination therapy in the adjuvant setting. Together these studies showed that addition of trastuzumab to adjuvant chemotherapy led to a $40 \%$ decrease in recurrence compared with chemotherapy alone [5]. Early results from one of these studies suggest that the combination of paclitaxel with trastuzumab gives improved outcomes over a sequence of paclitaxel followed by trastuzumab [6].

It is noteworthy that Clemens et al. report that 8 patients had newly diagnosed central nervous system (CNS) lesions at the time of detection of progressive disease. As demonstrated in this trial and others, trastuzumab improves outcomes in patients with HER2-positive breast cancer, but the CNS remains an important site of initial and subsequent relapse. Other targeted therapies, such as lapatinib have demonstrated activity for CNS metastases [7, 8]. In a phase III study evaluating capecitabine versus capecitabine plus lapatinib in women with HER2-positive metastatic breast cancer, the addition of lapatinib led to an improvement in outcomes and numerically fewer patients with symptomatic CNS progression as part of their first progression event $[9,10]$. New treatment ap-

\section{KARGER}

Fax +497614520714

Information@Karger.de

www.karger.com (c) 2010 S. Karger GmbH, Freiburg

Accessible online at:

www.karger.com/onk
Nancy E. Davidson, MD

University of Pittsburgh Cancer Institute and

UPMC Cancer Centers

5150 Centre Avenue, Suite 500, Pittsburgh, PA 15232, USA

Tel. +1 412 623-3205, Fax -3210

davidsonne@upmc.edu 
proaches are important for patients with CNS involvement, particularly for patients with HER2-positive breast cancer.

The results of the pivotal phase III trial that investigated the addition of lapatinib to capecitabine in patients with HER2-positive advanced breast cancer $[9,10]$ led to the US Food and Drug Administration's approval of lapatinib in combination with capecitabine for the treatment of patients with metastatic HER2-positive breast cancer that progressed after trastuzumab, anthracyclines, and taxanes. Lapatinib in combination with trastuzumab has demonstrated an improvement in overall survival compared to lapatinib alone in patients who have progressed on prior trastuzumab-containing regimens for metastatic breast cancer [11]. This study confirms a role for combined HER2 blockade. This study also demonstrates that lapatinib in combination with trastuzumab offers a chemotherapy-free option.

Other novel agents have also been evaluated in combination with trastuzumab. A phase II study of pertuzumab in combination with trastuzumab demonstrated an ORR of $24.2 \%$ in patients with metastatic breast cancer progressing after prior trastuzumab therapy [12]. This trial showed that the combination of pertuzumab and trastuzumab is active and well tolerated in patients with metastatic HER2-positive breast cancer who have progressed during prior trastuzumab therapy.
Studies are also evaluating trastuzumab-MCC-DM1 (TDM1), a conjugate of trastuzumab with the cytotoxic maytansine. A phase III trial is currently evaluating T-DM1 in comparison with the combination of capecitabine and lapatinib in patients with HER2-positive locally advanced or metastatic breast cancer who have received prior trastuzumab-based therapy [13]. Finally simultaneous targeting of multiple growth factor pathways is also a strategy of interest. Initial support for this approach comes from a phase II study demonstrating that the combination of trastuzumab and bevacizumab has a clinical response rate of $48 \%$ as first-line therapy in metastatic HER2-positive breast cancer [14].

In sum the results reported by Clemens et al. are a comforting validation of findings from another large phase II trial [3]. Together these trials demonstrate that single agent trastuzumab may be an option as treatment for HER2-positive metastatic breast cancer. Today trastuzumab is the foundation of treatment for women with HER2-positive disease in early stage breast cancer and it seems likely that continued development of targeted novel agents like trastuzumab will give hope for the future [15].

\section{Conflict of Interest}

The authors did not declare any conflict of interest.

\section{References}

1 Vogel CL, Cobleigh MA, Tripathy D, Gutheil JC, Harris LN, Fehrenbacher L, Slamon DJ, Murphy M, Novotny WF, Burchmore M, Shak S, Stewart SJ, Press M: Efficacy and safety of trastuzumab as a single agent in first-line treatment of HER2-overexpressing metastatic breast cancer. J Clin Oncol 2002;20:719-726.

2 Slamon DJ, Leyland-Jones B, Shak S, Fuchs H, Paton V, Bajamonde A, Fleming T, Eiermann W, Wolter J, Pegram M, Baselga J, Norton L: Use of chemotherapy plus a monoclonal antibody against HER2 for metastatic breast cancer that overexpresses HER2. N Engl J Med 2001;344:783-792.

3 Cobleigh MA, Vogel CL, Tripathy D, Robert NJ, Scholl S, Fehrenbacher L, Wolter JM, Paton V, Shak S, Lieberman G, Slamon DJ: Multinational study of the efficacy and safety of humanized antiHER2 monoclonal antibody in women who have HER2-overexpressing metastatic breast cancer that has progressed after chemotherapy for metastatic disease. J Clin Oncol 1999;17:2639-2648.

4 Clemens M, Eidtmann H, Nitz U, Niederle N, Du Bois A, Girschke E-M, Hinke A, von Minckwitz G: Trastuzumab single drug therapy after failure of cytotoxic treatment for metastatic breast cancer. Onkologie

5 Dahabrea IJ, Linardou H, Siannis F, Fountzilas G, Marray S. Trastuzumab in the adjuvant treatment of early-stage breast cancer: a systematic review and meta-analysis of randomized controlled trials. Oncologist 2008:13:620-30.

6 Perez EA, Suman VJ, Davidson NE, Gralow J, Kaufman PA, Ingle JN, Dakhil SR, Zujewski JA, Pisansky TM, Jenkins RB. Results of chemotherapy alone, with sequential or concurrent addition of 52 weeks of trastuzumab in the NCCTG N9831 HER2-positive adjuvant breast cancer trial. 2009 San Antonio Breast Cancer Symposium.

7 Lin NU, Carey LA, Liu MC, Younger J, Come SE, Ewend M, Harris GJ, Bullitt E, Van den Abbeele AD, Henson JW, Li X, Gelman R, Burstein HJ, Kasparian E, Kirsch DG, Crawford A, Hochberg F, Winer EP: Phase II trial of lapatinib for brain metastases in patients with human epidermal growth factor receptor 2-positive breast cancer. J Clin Oncol 2008;26:1993-1999.

8 Lin NU, Diéras V, Paul D, Lossignol D, Christodoulou C, Stemmler HJ, Roché H, Liu MC, Greil R, Ciruelos E, Loibl S, Gori S, Wardley A, Yardley D, Brufsky A, Blum JL, Rubin SD, Dharan B, Steplewski K, Zembryki D, Oliva C, Roychowdhury D, Paoletti P, Winer EP: Multicenter phase II study of lapatinib in patients with brain metastases from HER2-positive breast cancer. Clin Cancer Res 2009;15:1452-1459.

9 Geyer CE, Forster J, Lindquist D, Chan S, Romieu CG, Pienkowski T, Jagiello-Gruszfeld A, Crown J, Chan A, Kaufman B, Skarlos D, Campone M, Davidson N, Berger M, Oliva C, Rubin SD, Stein S, Cameron D: Lapatinib plus capecitabine for HER2-positive advanced breast cancer. N Engl J Med 2006;355:2733-2743.

10 Cameron D, Casey M, Press M, Lindquist D, Pienkowski T, Romieu CG, Chan S, Jagiello-Gruszfeld A, Kaufman B, Crown J, Chan A, Campone M, Viens P, Davidson N, Gorbounova V, Raats JI, Skarlos D, Newstat B, Roychowdhury D, Paoletti P, Oliva C, Rubin S, Stein S, Geyer CE: A phase III randomized comparison of lapatinib plus capecitabine versus capecitabine alone in women with advanced breast cancer that has progressed on trastuzumab: updated efficacy and biomarker analyses. Breast Cancer Res Treat 2008;112:533-543.

11 Blackwell KL, Burstein HJ, Sledge GW, Stein S, Ellis C, Casey M, Baselga J, O'Shaughnessy J: Updated survival analysis of a randomized study of lapatinib alone or in combination with trastuzumab in women with HER2-positive metastatic breast cancer progressing on trastuzumab therapy. San Antonio Breast Cancer Symposium: abstr 61, 2009.

12 Baselga J, Gelmon KA, Verma S, Wardley A, Conte P, Miles D, Bianchi G, Cortes J, McNally VA, Ross GA, Fumoleau P, Gianni L: Phase II trial of pertuzumab and trastuzumab in patients with human epidermal growth factor receptor 2-positive metastatic breast cancer that progressed during prior trastuzumab therapy. J Clin Oncol 2010;28:1138-1144.

13 Clinical trial: an open-label study of trastuzumabMCC-DM1 (T-DM1) vs. Capecitabine + lapatinib in patients with HER2-positive locally advanced or metastatic breast cancer (EMILIA). http://clinicaltrials.gov/ct2/show/NCT00829166. Accessed June 26, 2010.

14 Hurvitz SA, Pegram MD, Lin L-S, Chan DS, Allen HJ, Dichmann RA, Hagenstad CT, Barstis J, Hermann RC, Hu EH, Moroose RL, Thomas SP, Vogel CL, Ryba N, Elashoff D, Slamon DJ: Final results of a phase II trial evaluating trastuzumab and bevacizumab as first line therapy of HER2amplified advanced breast cancer. San Antonio Breast Cancer Symposium: abstr 6094, 2009

15 Barth J, Jackisch C, Untch M: Antibodies and tyrosine kinase inhibitors in breast cancer therapies. Breast Care 2009;4:46-50. 